How do faculty members' social group identities influence their choices about how they present themselves and their course materials? How do these identities affect student responses to them and the material they present?

\title{
Faculty Members' Social Identities and Classroom Authority
}

\author{
Mark Chesler, Alford A. Young Jr.
}

Social group identity is as relevant to the teaching-learning enterprise as it is to thought and behavior in all other walks of life. Membership in social groups identifiable by race or ethnicity, gender, age, and other characteristics affects the ways in which we think and act and the ways in which others perceive us, act toward us, and react to us. Specifically, we know that faculty members with different social group identities experience the academy differently and have varied reactions to those experiences. Several major studies and a number of first-person anthologies testify to different rates of representation, status or rank, level of satisfaction, approaches to the classroom and curriculum, encounters with students, and relationships with colleagues (Adams, Bell, and Griffin, 1997; Banks and Banks, 1995; Castellanos and Jones, 2003; Dews and Law, 1995; Hune, 1998; Li and Beckett, 2006; Lim and Herrera-Sobek, 2000; Macdonald and Sánchez-Casal, 2002; Maher and Tetrault, 1994; Mayberry, 1996; Padilla and Chavez, 1995; Stanley, 2006a; Turner and Myers, 2000; Valian, 1998; Vargas, 2002). Overall, the power of whiteness and maleness as identities privileged by academic institutions' cultures and structures provides the context within which individual faculty members encounter and respond to diverse students and their actions in and out of the classroom.

In this chapter we examine how the social group identities of faculty members are reflected in their pedagogical encounters and practices. More particularly, we consider how faculty members with different social group 
identities deal with two issues commonly faced by all faculty: questions about their subject matter expertise and questions about the authority of the faculty role. Both areas are often the grounds on which students covertly or overtly challenge faculty authority.

In exploring these issues we conducted face-to-face interviews with a sample of 64 faculty members at a major midwestern research extensive university. A diverse sample (by race or ethnicity, gender, and discipline) of faculty was recruited for these interviews ( 32 females and 32 males; 18 whites, 20 African Americans, 13 Asian Americans, 9 Latinos and Latinas, and 4 Native Americans; 25 social scientists, 22 natural scientists, and 17 humanists). Faculty were selected on the basis of their local reputations as outstanding instructors and as especially thoughtful practitioners of teaching in diverse classrooms. Thus no attempt was made to gather a representative sample; rather, the aim was to solicit the most advanced thinking and experience on these issues from what is in many ways a particularly sophisticated cadre. Many of these individuals have won teaching awards, and all express a commitment not just to teaching but to teaching effectively in a diverse environment. As result, these faculty may be more aware of, sensitive to, and adept at dealing with these issues than their colleagues.

The excerpts presented here reflect faculty members' own perceptions and interpretations-not those of their students and colleagues-as received, organized, and interpreted by the authors.

\section{Assuming, Asserting, and Dealing with Academic Expertise and Challenges to It}

As the dominant face of the faculty, white and male faculty members can make-and can assume that students will make-assumptions about the high level of their subject matter expertise. Very few of the white faculty interviewed anticipated or encountered a challenge to their expertise. Indeed, when faced with the occasional student challenge, one white male faculty member indicated that he felt he could afford to be challenged and even to make mistakes: "I can make errors; I can make mistakes; I can have a bad day; I can be disorganized; I can use terms incorrectly; and most faculty of color cannot."

Other tenured white faculty also expressed relative comfort in addressing perceived or potential conflicts with students over course material. As one white female colleague who teaches about race and ethnicity stated, "I have a lot of authority in the classroom, but I also create an atmosphere so that if students are unhappy, they feel completely at ease to tell me they're unhappy. . . . I don't think that if I was a male, I would get students coming at me. But I've definitely had conflicts over authority, conflicts with men in the classroom. I learned a lot from that stuff." Thus while acknowledging conflict and potential challenge and their relation to her gender, this white colleague also indicates that she knows how to deal with their occurrence with relative comfort. 
The tension and anxieties experienced by faculty of color were not so easily resolved or managed. In part, this is due to the social reality that upon standing in the front of a classroom, these faculty immediately and starkly became visible examples of difference for their students. For instance, two African American male natural scientists discussed their experiences as follows. One confided, "In a sense, I lack a kind of authority. There are certain students that I have to prove myself to. There are students who I think are not prepared to accept me as an authority on the subject matter, whether it's because of my race or my politics." The other noted, "When I walk into the classroom, my anticipation is that I will be challenged; that's why I've got to be prepared, and I think that with that philosophy it's easier for me to be well prepared because I expect and anticipate, you know, the worst." The first colleague's statement reflects the dilemma, common to faculty of color, of knowing that his expertise is questioned by students but not knowing clearly whether that is a function of his race or other aspects of his persona. The second colleague clearly expresses the anticipatory vigilance and even sense of dread accompanying his entry into a challenging and potentially disconfirming environment.

Purwar (2004) argues that "authority is seen to be especially misplaced when it is clearly vested in a woman of color" (p. 52), and several female faculty members of color reported their experiences in this regard. In one case, an Asian American colleague discussed the relatively narrow grounds on which she expected her expertise to be accepted by students: "I also think that if students know, for example, that I do Asian American studies ...., then somehow they perceive me as less able to talk about a range of other issues. So they would perceive that I don't know how to read white scholars. Or that whenever we do read white scholars, you can sense this little surprise, like, 'Oh, she can do that too."

An African American female social scientist reported that she acted very early in the semester to avoid or neutralize potential challenges to her expertise: "I do my background routine. I tell them I have these degrees. . . . 'I may be the first black face you've ever seen, but there are a lot of us with Ph.D.'s, and I have one.' It's totally mind-boggling for some folks." This colleague is aware of her anticipation of being challenged by students and takes steps to prevent or foreclose it. Her prior experience with challenge and ensuing personal discomfort or classroom disruption has led her to respond by getting her credentials on the table at the outset.

With experience, and with the added weight of age, some of these challenges to expertise may recede or become easier to deal with-at least, that was the perspective of a female African American natural scientist, who said, "It's a little different now that I've got a little more maturity and a few gray hairs. ... It was most challenging when [I was] green, just starting, and it's easy for students to kind of dismiss faculty of color, if they see that there are other ways to get the information, or to discount your knowledge and your 
experience." Younger faculty, younger female faculty, younger faculty of color, and especially younger female faculty of color consistently report more challenges to their substantive expertise and more pain and discomfort (sometimes anger as well) in dealing with those challenges.

The foregoing comments demonstrate that challenges to a faculty member's standing as a subject matter expert can occur to anyone, regardless of race, gender, or seniority. However, the racial, gender, and seniority status of professors directly affects the degree to which they are challenged about what or how much they know about their topic and the manner in which they interpret and respond to such challenges (including whether they feel inclined or obliged to respond at all).

\section{Dealing with Institutional Role and Authority and Challenges to Them}

The same pattern holds regarding faculty members' differential assessments of how they deal with challenges to their role and authority status in the classroom. Faculty who possess social identity characteristics that are not privileged spoke of having to force recognition of their professional role and the deference that faculty generally believe should accompany it. For instance, in assessing her experiences and struggles in comparison to other professors in the university classroom, a white female colleague stressed the importance of gender: "I think men have it way too easy in the classroom. They don't have a clue how much harder it is to have authority and to get respect and to just not have to deal with a lot of bull-from some students." Another white female natural science scholar said, "I can't get away with saying things like 'Shut up' [because] there are huge gender differences in what students expect of a teacher. They would not call a male instructor on that. But they would call a woman on that. If a woman did that, there'd be immediate complaints that would affect the whole semester." She went on to report that students' preconceived notions of gender roles can influence their expectations of faculty and their perceptions of whether faculty members are meeting these expectations: "I cotaught with a male one semester-he had no office hours, [and] he answered no e-mails. He did teach the class. [Yet at the end of the semester,] he got higher scores on accessibility [and] on evaluations than I did! I had office hours even when he was lecturing. I answered every e-mail. The students came to my office hours. My accessibility score was lower. And that's a difference in expectation."

These perceptions of accessibility and the character of student-faculty interpersonal relationships are exacerbated when less privileged racial and gender statuses are in play. As one Latina scholar said, "Different faculty take certain hierarchical positions which affect the whole question of what they're supposed to call me-Professor XXX, my first name, or whatever. It has everything to do with how old I am, my gender, my race. The reality is 
I'd prefer if they'd call me Professor XXX. But they don't usually. They call me by my first name."

A second female faculty of color indicated how she more directly addressed such actual as well as potential challenges to her status and how some students tried to relate with her. In one instance, a student left a message after hours on her answering machine stating that she planned to join the class and demanding that the faculty member call her back to specify the readings for the next day. "And why would she think that I would be around to just pick up the phone? Because people do assume, particularly with African American women, that we are their 'mamas,' and some of them go so far as to say things like that. And I say, 'I'm a warm person, I'm a kind person. . . . I know this may be the first black woman you've interacted with except your maid, but I'm not your maid." She planned to have a face-to-face encounter with this student, a strategy she uses regularly to address such challenges to her authority. Among the key dilemmas reported are the tension between authority and warmth or kindness and the ways in which accessibility, warmth, or innovation by female scholars and scholars of color may be interpreted and reacted to by students as signs of weakness or loss of traditional forms of authority.

It is important to note that some faculty of color indicated that challenges to their status and authority did not come exclusively from white students. As one African American woman said in discussing the consequences of bringing her personal experiences into the classroom, "I've had students [of color] after class come up to me and hug me. I'm not a touchy-feely person. . . . It makes me very uncomfortable. I think they mean it positively, but I also wonder if they mean it as, 'Well, we're both black, and there's some connection.' So ... I simply say, 'I'm not unreasonable, [but] look, I'm your teacher; you're my student; we're not friends."'

These cases demonstrate that challenges to a faculty member's institutional role or authority status do not have to take the form of aggressive or pernicious interactions. Alternatively, challenges can take the form of students' trying to reposition faculty members as fulfilling supportive, nurturing, or intimate roles rather than professional ones. This is done, or at least expected, precisely because such faculty members stand in social identity categories that have not been traditionally associated with faculty status in the academy.

Another African American female scholar explained her own way of dealing with these issues by indicating that she forthrightly asserted and maintained a position of authority. She said, "The first thing is to set the tone in the first class session that you are in charge. Don't ever let that slip, because the moment you do, because you are a person of color, you will never regain that. It's a cliché that to a certain extent that if you are a person of color you have to come doubly prepared, because you will get challenges in classroom settings that your peers simply won't ever great."

In pulling together the effects of race or ethnicity and gender on challenges to institutional authority and how this can be handled (at least to 
some extent), a female scholar of color explained that appearance mattered as much as conduct in her effort to establish her authority in the classroom: "How can a nonwhite woman assert authoritativeness in a classroom dominated by white males for whom authority figures have been largely other white males? ... Attire is a big part of it. I'm always conscious of how I dress on teaching days."

These comments contrast with the sentiment of a senior African American male professor who explained with relative ease how he functions in his classroom and how that compared with what he believes female faculty of color have to confront in that setting: "I let the students start off. And so long as I can get them where I want them to go without telling them, you get the same result each time, but never the same route. And that's easy, see; that's fun. . . . And when I mention this to younger colleagues ...., especially black women, [they] can't fathom going into a classroom that way. Because ... they're concerned that their authority will be undermined. They say, 'You're male and you're older."'

In a comment that further clarifies what the differences in respect and deference to authority often are for white scholars and scholars of color and how race, gender, and age operate simultaneously in this circumstance, an Asian American female scholar said the following:

I always admired professors who were kind of older-senior men usually. . . . They have a lot more authority, but also they're able to be kinder in the classroom or to be more generous to their students. ... Whereas I'm kind of a small person, right? And a woman and Asian, right? So it's almost the opposite of the ideal teacher. So I would like to be kind and generous and be perceived to be that way. But often I feel like the only way that I can do that is if I appear very old as a way to kind of offset those things.

These comments demonstrate that mastery of course content is far from all that is necessary to ensure that faculty of color and female faculty secure the kind of respect and deference that is accorded to higher education faculty who occupy more privileged identity categories. Aside from matters concerning the depth or extent of a professor's scholarly expertise, there remains the issue of what it means for professors to appear in front of a classroom in possession of bodies that do not match the image that many students associate with the professoriate.

\section{Discussion and Implications}

The ultimate pedagogical dilemma for faculty who face this situation, then, is to work at ensuring and preserving the authority that has a place in relationships with students while also maintaining a healthy and vibrant educational climate. Moreover, they may wonder whether they really are being 
challenged more often than white males, whether those they do face are imbued with more intensity or hostility, or whether they are simply more sensitive to challenges that do occur.

White male (and senior) faculty who do not encounter the same challenges or who do not interpret or react to them in the same way may be puzzled by these reports from female colleagues and colleagues of color and not know how to deal with them. It may seem as though faculty in subordinate categories are less competent or that they imagine these problems or create them themselves. However, the situation requires that white and male peers and administrators understand that these challenges emerge in very different ways and potencies for different kinds of faculty.

Where does one go for help and support in dealing with such challenges? What would help? Particularly good resources for a wide range of answers to these questions can be found in Moody (2004) and Stanley (2006b). But in the midst of a culture of assumed expertise and surrounded by a generally lower priority of teaching in general, let alone teaching competently in a diverse classroom, advice, assistance, and support may be hard to come by at the local level. Most young faculty receive little instruction or mentoring about teaching and none at all about the unique ways in which the social identities of faculty and students may play out in the classroom.

Workshops and faculty development programs for graduate students and young faculty may help some of the abstract information about managing one's expertise and role become concrete and realistic. Then female faculty and faculty of color may anticipate some of the relatively unique issues they will face and can plan their approaches to the classroom and their responses to potential challenges. Cadres of female faculty and faculty of color can be encouraged to meet and share their experiences and approaches with one another. It is crucial for these faculty members, above all, to be true to themselves and to find ways of teaching and of meeting the challenges of teaching that reflect their own personal and cultural styles and priorities. For some that may mean facing such challenges directly and pointing out to students the racial and gender assumptions underlying their responses; for others it may mean avoiding direct engagement and focusing on traditional instructional content and pedagogies.

And some attention must be paid to students and the expectations they bring into the diverse collegiate environment. Orientation programs may help prepare students to anticipate, recognize, and deal with their own and their peers' often implicit or subconscious perceptions and biases of faculty members of diverse backgrounds.

In addition, discussions with senior white and male faculty can provide an opportunity to share the wisdom of experience and help establish greater understanding of the particular issues that female faculty and faculty of color are likely to encounter, including the potential impact of race and 
gender status on student ratings of faculty (see Basow, 1998; Kardia and Wright, 2004). Members of more privileged groups may then take some responsibility for establishing a departmental or collegiate culture of respect and mutual support that makes life easier for all faculty. As long as the academy remains a white and male hegemonic site, nothing less than major efforts at culture change will fundamentally address the inequities faced by female faculty and faculty of color. The classroom and the academy itself are creatures of the larger society, and all the broader struggles around affirmative action and race and gender in higher education constitute background for the issues discussed in this chapter.

\section{References}

Adams, M., Bell, L. A., and Griffin, P. (eds.). Teaching for Diversity and Social Justice: A Sourcebook. New York: Routledge, 1997.

Banks, J. A., and Banks, C.A.M. (eds.). Handbook of Research on Multicultural Education. Old Tappan, N.J.: Macmillan, 1995.

Basow, S. A. "Student Evaluations: Gender Bias and Teaching Styles." In L. H. Collins, J. C. Chrisler, and K. Quina (eds.). Career Strategies for Women in Academe: Arming Athena. Thousand Oaks, Calif.: Sage, 1998.

Castellanos, J., and Jones, L. (eds.). The Majority in the Minority: Expanding the Representation of Latina/o Faculty, Administrators and Students in Higher Education. Sterling, Va.: Stylus, 2003.

Dews, C.L.B., and Law, C. L. (eds.). This Fine Place So Far from Home: Voices of Academics from the Working Class. Philadelphia: Temple University Press, 1995.

Hune, S. Asian Pacific American Women in Higher Education: Claiming Visibility and Voice. Washington, D.C.: Association of American Colleges and Universities, 1998.

Kardia, D. B., and Wright, M. C. "Instructor Identity: The Impact of Gender and Race on Faculty Experiences with Teaching." CRLT Occasional Papers no. 19. Ann Arbor: University of Michigan Center for Research on Learning and Teaching, 2004.

Li, G., and Beckett, G. H. (eds.). Strangers in the Academy: Asian Women Scholars in Higher Education. Sterling, Va.: Stylus, 2006.

Lim, S., and Herrera-Sobek, M. (eds.). Power, Race, and Gender in Academe: Strangers in the Tower. New York: Modern Language Association of America, 2000.

Macdonald, A. A., and Sánchez-Casal, S. (eds.). Twenty-First-Century Feminist Classrooms. New York: Palgrave Macmillan, 2002.

Maher, F. A., and Tetrault, M.K.T. The Feminist Classroom: Dynamics of Gender, Race, and Privilege. New York: Basic Books, 1994.

Mayberry, K. J. (ed.). Teaching What You Are Not: Identity Politics in Higher Education. New York: New York University Press, 1996.

Moody, J. Faculty Diversity: Problems and Solutions. New York: Routledge, 2004.

Padilla, R. V., and Chavez, R. C. (eds.). The Leaning Ivory Tower: Latino Professors in American Universities. New York: State University of New York Press, 1995.

Purwar, N. "Fish in or out of Water: A Theoretical Framework for Race and the Space of Academia." In I. Law, D. Phillips, and L. Turney (eds.), Institutional Racism in Higher Education. Sterling, Va.: Trentham Books, 2004.

Stanley, C. A. (ed.). Faculty of Color Teaching in Predominantly White Colleges and Universities. Bolton, Mass.: Anker, 2006a.

Stanley, C. A. "Summary and Key Recommendations for the Recruitment and Retention of Faculty of Color." In C. Stanley (ed.), Faculty of Color Teaching in Predominantly White Colleges and Universities. Bolton, Mass.: Anker, 2006b. 
Turner, C.S.V., and Myers, S. L., Jr. Faculty of Color in Academe: Bittersweet Success. Boston: Allyn \& Bacon, 2000.

Valian, V. Why So Slow? The Advancement of Women. Cambridge, Mass.: MIT Press, 1998. Vargas, L. (ed.). Women Faculty of Color in the White Classroom: Narratives on the Pedagogical Implications of Classroom Diversity. New York: Lang, 2002.

MARK CHESLER is emeritus professor of sociology at the University of Michigan.

ALFORD A. YOUNG JR. is associate professor of sociology and Afroamerican and African studies at the University of Michigan. 